The Geneva Papers on Risk and Insurance, 22 (No. 84, July 1997) 314-326

\title{
Private Versus State Systems for Industrial Accidents: The Belgian Case
}

\author{
by Claude Desseille*
}

\section{Introduction}

It is generally agreed that it is incumbent on the State to define the social risks and to opt for an adequate structure and management system.

The "Industrial Accidents" risk guarantees the granting of a benefit which is part of the workers' social protection system laid down by the legislator.

In that meaning, the "Industrial Accidents" risk is an eminently social risk; it is a social security insurance. Let's notice that the word "social risk", which refers to the type of benefit and to the contents of the cover, is preferred to the word "branch of social security" which leads to a double meaning: the latter refers to the type of benefit as well as the insurance system chosen to cover that particular benefit.

Regarding the choice of an adequate structure, the question is whether that industrial risk must be covered by a specific kind of insurance and whether it must be compensated for on different bases than the private life accident risk.

Two European countries (the Netherlands and Greece) don't make any distinction according to whether the accident or the sickness has its origin in the work or not. In both cases the costs are borne on the same bases.

In all other E.U. countries the employer is supposed to bear the risk related to his employees' work. That work-related risk is indemnified on different bases than those of a private life accident. Some European countries have chosen to integrate that social risk into their State's social security structure. In other countries (Belgium, Denmark, Finland, Spain, Portugal) the insurance of the industrial risks has been entrusted to private insurers or professional mutual benefit insurance systems.

In Belgium, the legislator has chosen a coexistence system of two structural systems to cover the social risks.

All social risks, on the one hand, except for the industrial accident, i.e. "Private Life" sickness and disability, occupational disease, unemployment, retirement, child benefits, holiday allowance are managed by the State within the scope of the social security.

\footnotetext{
* Directeur Général de Winterthur-Europe Assurances.
} 
The management of the "Industrial Accidents" risk, on the other, has been entrusted to private insurers: they underwrite and manage insurance contracts. They settle the claims and are financially liable for the loss management.

Moreover, the Belgian legislator has also opted for a coexistence of laws. The industrial accident insurance is characterized by a double legal relation: the "insurer-employer/policyholder" relation of contractual nature governed by the law of 25.06 .1992 on the land insurance contract on the one hand and the "insurer-victim" relation of indemnity nature governed exclusively by a specific law, that is the law of 10.04.1971 on the industrial accident on the other.

Each of these relations falls within the scope of an own specific legal environment which is not contradictory but complementary.

\section{Industrial accident management system}

\subsection{History}

From the beginning onwards, the industrial accident insurance has been considered as a liability insurance. Before the first law on the compensation for industrial accidents was created in 1903 the industrial accident victims could have their damage compensated for only according to the rules of the common law civil liability as fixed in articles 1382 and following the Civil Code: they had to prove either a fault on account of those whom they wanted to be indemnified from or a defect in the material used.

Since the employer's or workmates' liability is not easy to establish and since the work relation might be disturbed by this kind of action, the legislator has found a remedy for these inconvenients through the law of 24.12.1903 (enforced on 01.07.1905).

That law starts from the notion that the employer, who employs workers in favour of his firm, must support the risks linked to their work. That law was innovated by setting up a system of objective liability in which the employer is considered to be automatically liable for the industrial accidents occurring in his firm without the victim having to establish any fault.

Moreover, the integral compensation for the damage as determined in common law has been replaced by a lump sum, as the indispensable consequence of the newly established objective liability.

In 1903 the insurance was still optional. The insurance wasn't compulsory until 1971 and since then the victim has a right of direct action against the insurer instead of a simple action against the employer. Furthermore, the direct action principle has been generalized in all the liability insurances since the law of 25.06 .1992 on the land insurance contract.

\subsection{Indemnity relation insurer-victim: law of 10.04 .1971}

\subsubsection{Characteristics}

\section{Public character}

Article $6, \S 1$ of the law says that the nullity of the contract for services may not be opposed to the application of the law. In case of a null labour contract (for example: employment of children under the age of 14 , foreigners without a work permit, casino employees...) the worker will be covered by the employer's insurer. 
Article $6, \S 2$ of the law says that "any agreement contrary to the legal provisions is null by right". The employer is not allowed to agree with his employees on a lower compensation in case of an industrial accident and he is also not allowed to agree on a more attractive compensation system. However, the employer may grant advantages by contract or even voluntarily complementary to those legally granted by taking out an insurance considered to be "complementary to the law".

To make sure that this principle will be efficiently applied the judge to whom a conflict has been submitted, automatically checks whether the legal provisions have been respected (art. 6, §3).

\section{Compulsory character}

Article 49, par. 1 of the law states that the employer must take out an insurance against the industrial accidents either with an approved fixed-premium insurance company or with an approved common insurance fund. The non-insurance leads to the automatic affiliation and to the recovery of the indemnities paid by the Fund for Industrial Accidents.

\section{Inclusive character}

Contrary to the common law, indemnification which compensates for the whole really suffered loss the industrial, accidents are indemnified on an inclusive basis (legal maximum basic salary, decrease in the compensation and non-indexation for the permanent disabilities of less than $10 \%$, payment of $90 \%$ of the total temporary disabilities...).

\section{Insurance unity}

Under article 49, par. 7 and 8 the employer must take out an insurance in favour of all his workers for all their duties. The employer must not split the insurance of one category of workers (workmen, employees) over several insurers.

\section{Social character}

The law on the industrial accidents has set up different mechanisms seeking to guarantee the objective of the workers' social protection: no forfeiture clause arising from the insurance contract (for example: suspensions of the cover in case of non-payment of the premium) may be imposed on the victim by the insurer; only the jurisdiction in the industrial dispute are qualified to decide upon a dispute; all management and proceeding costs (even if the proceedings have been initiated by the victim) are payable by the insurer; the victim is given the benefit of the doubt, which lightens the evidence he/she has to bring forward as proof of the industrial accident; the indemnities paid to the victim are classed as salaries, it being understood that only a well-defined amount may be seized or transferred.

\subsubsection{Insured persons}

The philosophy of the law is to have the application of the law on the industrial accidents and that of the Social Security legislation coincide. The law applies to any individual subjected to social security.

The King has extended the application of the law to some workers who are excluded from social security:

Managers and Directors of associations (mutual benefit insurance companies, trade unions, ...), actors of remunerated shows, temporary workers, some workers at home, students, some professional sportsmen (racing cyclists, football players), occasional workers or workers who exercise a secondary occupational activity, servants. 
The excluded professions are: members of the liberal professions, tradesmen and other self-employed workers, and directors of companies. All civil servants and servicemen are covered by a law particular to the public sector (law of 03.07.1967).

\subsubsection{The industrial accident notion}

The Court of Cassation has defined the industrial accident as a sudden event provoking a body injury (incapacity to work or death) and whose cause or one of the causes is external to the victim's body. The victim must, first of all, establish that there was an accident before proving that it is indeed an industrial accident or an accident on the way from and to the work place.

a) Article 9 of the law states that the victim only needs to prove the existence of an injury and the existence of a sudden event, being the criterion according to which the accident can be distinguished from a sickness. When those two facts are established the victim is given a first presumption that there is a causal relation between the injury and the accident which means that the injury was caused by the accident. The insurer may reverse that presumption.

b) Then, article 7 of the law states that the victim must prove that the accident occurred during the fulfilment of the labour contract, that is when the victim was under his employer's authority.

The victim is not given a second presumption that the accident happened because of the fulfilment of the labour contract and that it is indeed an industrial accident. The insurer may also reverse that presumption.

The burden of proof normally lying with the victim has been significantly lightened.

c) The accident occurring on the way to and from the work place (art. 8) is also covered. The victim must prove that he/she was on the normal way from his/her residence (which is not necessarily the domicile) to the place where the labour contract is fulfilled. The law provides for a series of extensions (place of vocational training, place where the worker has his meals or spare times in mission, carpooling, way travelled to drive the children to or collect them from school ...). When the victim has proved that he/she was on the way to and/or from the work place, he/she is automatically indemnified.

\subsubsection{Compensation}

\subsubsection{Inclusive compensation}

The law enumerates restrictively the damage giving right to compensation and the owed indemnities and benefits.

The victim's and close relatives' psychological damage does not give right to compensation.

\subsubsection{Medical costs, prostheses, travelling expenses}

- The insurer bears the costs of the medical, surgical, pharmaceutical and hospitalization care required after the accident and this during the victim entire recovery period, applicable to all accidents occurring after 1.1.1988. These costs are reimbursed to those who bear them.

It is important to underline that the victim freely chooses the doctor, or the hospital. 
The tariff for the reimbursement of the medical care corresponds and is limited to the tariff of the fees and prices which are set for compulsory sickness and disability insurance (National Institute of Sickness and Disability Insurance barema).

In the theoretical assumption that the insurer or the employer had organized a health care service, the victim would no longer be free to choose but would benefit from a total reimbursement.

- The costs of the prostheses required by the industrial accident are borne by the insurer. Prosthesis is understood to include all artificial medical aids which a valid person does not need and which are necessary to support and replace disabled or weakened parts of the body or to favour their use or their function.

The insurer provides for the adequate prosthesis and establishes a capital intended for its future maintenance and renewal.

The insurer also indemnifies the existing prostheses broken in an industrial accident even if the accident has not provoked additional injuries.

- The victim, but also the spouse, the children and the relatives under certain conditions, are entitled to compensation for travelling expenses required by the accident (summons to appear before the insurer's consulting doctor, before a legal expert, before a doctor of the Fund for the Industrial Accidents, for medical reasons, ...).

\subsubsection{Total temporary incapacity}

As soon as the victim is no longer able to fulfil the function he/she exercised with the employer before the accident, he is considered to suffer a total temporary incapacity. The duration of this incapacity may be controlled at any time by the insurer.

During the whole period of incapacity the victim is entitled to a daily indemnity calculated on the basis of $90 \%$ of the salary paid the year before the accident and limited to a yearly maximum (for 1997: 927 '540 BEF). It being understood that the guaranteed salary is reimbursed to the employer.

\subsubsection{Partial temporary incapacity}

The victim might keep a certain capacity to work either in the profession he/she exercised at the time of the accident or in another profession. The aim of the indemnification system set up is not only to guarantee the salary the worker was paid before the accident but also to punish him if, without any valid reason, he refuses or interrupts the work proposed to him. The victim is thus entitled to an indemnity equivalent to the difference between his salary before the accident and the one he has been paid since he has resumed his work. It is the real loss of salary which is being compensated for.

The indemnities for total or partial temporary incapacity are indexed after a period of three months as from the day of the accident.

\subsubsection{Permanent incapacity}

- The permanent incapacity to work is assessed according to all the professions which the victim is still able to exercise regularly. That is to say, according to the general situation of the labour market by taking into account some social and economic data particular to him (his age, his vocational qualification, his ability to adapt himself, his competitiveness, ...). 
- The victim is entitled to an allowance calculated according to the basic salary and to the degree of incapacity, from the consolidation onwards, that is from the medically determined time when the incapacity reveals itself permanent. The starting point is determined from an agreement between the parties confirmed by the Funds for the Industrial Accidents or by a judicial decision which serves as a final judgment.

- The allowance for the incapacities lower than $10 \%$ is decreased by $50 \%$ if the incapacity rate is lower than $5 \%$. It is decreased by $25 \%$ if the rate reaches $5 \%$ and is lower than $10 \%$ and is complete if the rate reaches $10 \%$ and is lower than $15 \%$. The allowances are not indexed and are paid annually.

- For the incapacities of more than $10 \%$ the allowances (or annuities after the revision period) are indexed, they are paid monthly and one third of the annuity maximum may be surrendered in lump sum. So the Belgian system does not know the excess system.

\subsubsection{The assistance of a third party}

If the victim's state requires absolutely and normally the assistance of a third party, a complementary allowance is due according to the degree of necessity. The third party's loss of salary is legally presumed and justifies the granting of the complementary allowance.

The allowance is fixed according to the degree of necessary assistance and its annual amount may not exceed the guaranteed average monthly minimum income multiplied by twelve (in 1996: 523,980 BEF). The allowance is no longer due for an hospitalization from the third month on.

\subsubsection{Death}

The law provides for three categories of compensation following the victim's death, whether this death occurred immediately or after a period of incapacity:

- an indemnity for funeral costs equal to thirty times the average daily salary. This is a lump sum independent from the real cost price of the funeral costs. That lump sum is paid to the one who has actually borne the costs;

- the real costs for the transport of the mortal remains to the burial place and the administrative formalities;

- indexed annuities which are due from the date of the victim's death to certain assignees: the surviving spouse (life annuity equal to $30 \%$ of the basic salary), the children (temporary annuity of 15 to $20 \%$ of the basic salary with a maximum of 45 to $60 \%$ until the age of 18 or as long as the children are entitled to the child benefits), the relatives, the grandchildren, the brothers and sisters.

The surviving spouse may ask to be paid one third maximum of the annuity value in lump sum.

\subsubsection{Combinations with other social benefits}

- Retirement and survivors' pension: partial combination. The industrial accident allowances and annuities are limited. The difference must be paid by the insurer to the Fund for the Industrial Accidents. 
- Sickness and disability insurance: the combination is allowed if the sickness and disability insurance benefits are due because of an ailment or injury different and independent from the Industrial Accident.

- Child benefits: combination allowed.

- Industrial Accidents: combination allowed.

- Allowances for the disabled people: combination not allowed.

- Unemployment benefits: combination allowed providing that the victim is capable of working (P.I $<66 \%)$.

- Holiday allowances: possible combination of the allowances and annuities for a permanent incapacity and the holiday remuneration.

\subsection{Insurer-employer/policyholder relation: law of 25.06.1992}

As reminded by the Council of State in its opinion about the Government bill of the law of 10.04.1971, the law on the industrial accidents is an insurance which includes the three essential elements, being the contract, the payment of the premiums and the risk.

Since the industrial accident insurance certainly is a land insurance, there is no doubt that the law of 25.06.1992 applies to that insurance.

What is it for an insurance? Regarding the historical philosophy of that insurance, the industrial accident insurance unquestionably is an insurance covering the employer's liability towards his workers in case of industrial accidents.

That classification in the category of the liability insurances and more widely in the category of the damage insurances is confirmed by the fact that the compensation for the industrial accidents surely has an indemnifying character depending on the importance of the damage even if the modalities of those compensation are inclusive.

Like in all civil liability insurances there are three interveners: the insurer, the policyholder and the beneficiary of the indemnity. Unlike in the other civil liability insurances, in industrial accident insurances the beneficiary does not have a right of recourse against the objectively liable employer.

- "Insurer" means either fixed-premium companies, trading companies applying preestablished premiums, or common funds set up in mutual insurance associations in which the members (the employers) participate one another, each of them for their contribution to the results.

- "The employer" is a real policyholder within the meaning of the law of 25.06.1992: he takes out the insurance, he decides over its cancellation and he is the only debtor of the insurance premiums.

In their contractual relationship, the insurer as well as the employer must respect the mandatory rules of the law on the land insurance contract (as far as the law on the industrial accidents, which is a specific law, does not go against it) and, in particular, those relating to the conclusion of the contract (notification of the risk) to the fulfilment of the contract (notification of the increased risks, payment of the premiums, notification of losses) and to the cancellation of the contract (duration, cancellation after a loss, bankruptcy, ...). 


\subsection{Financial aspects}

\subsubsection{Financing}

Financing is totally independent from the ONSS (National Office of Social Security). In a private insurance system the insurers are indeed financially responsible for the management of the risks they cover. A premium is negotiated with the policyholder often through a broker.

An adequate fixing of a price scale depends not only on the nature of the "risk" to be covered but must also be adapted to the loss ratio particular to the enterprise.

Three risk categories are generally distinguished: the risk "workman", the risk "employee" and the risk "way to and from the work place". The principles of the fixing of a price scale are different for each of those risks.

The professional Union set up a new tariff structure for the "workman" occupational risk in 1992.

"Risk" is also understood to include the nature of activity practised by the company to be insured. The premium rates do change according to the activity sectors (NACE code).

As far as the industrial accidents are concerned the premiums are calculated on the basis of the salaries declared by the enterprise. The insurer issues provisional premium receipts and definitively regularizes the account at the end of the year according to the salaries paid during the whole year.

\subsubsection{Financial management}

The financial management is characterized by the application of the accounting rules, which plan the outlay that the insurers will have to cope with in the very long term.

The industrial accident insurances produces significant reserves built up case by case (in 1993: about 167 billion).

The financial system enforced in Belgium is the capitalization system. By the immediate building up of the necessary capital that system secures that the insurer honours his life promises of indemnification. The victims have a preferential right over that capital.

\subsubsection{Taxation}

- Regarding the victim: all benefits except for the assistance to a third party and the medical costs are taxable. The insurer must deduct income tax from the wages and establish fiscal index cards. The victim, however, benefits from a tax reduction system.

- Regarding the insured enterprise: the premiums paid are fiscally deductible.

\subsection{Relations between the insurers: European directives}

Since the industrial accident insurance is an insurance of its own, practised by private insurance companies, it undoubtly falls within the scope of the European directives on insurances.

The third directive in Non-Life insurance of 18.06.1992 deals with the free movement of service and provides for specific provisions for the compulsory insurances (Art. 30 and 32) and among others also for the industrial accident insurance (Art. 55). The Member States may ask any insurance company wishing to practise the industrial accident insurance in Free Movement of Service on their territories to respect the specific provisions laid down 
by their national law for that kind of insurance, except for the provisions relating to the financial supervision. The Belgian State could oblige the foreign insurers to abide by the public rules stipulated in the law of 10.04.1971 (in this way the objective of social protection of the victims would be reached) but could not ask the foreign insurers to respect the provisions about the financial supervision which the Belgian insurers are subjected to.

Therefore, the Belgian State refuses to agree that the Industrial Accident insurance as practised in Belgium falls within the scope of the European directives.

That refusal is amazing since we know that, according to article 45 of the third Directive, the Member States have the opportunity "to compel the companies exercising their activities on the Member States' territories, under the same conditions as the companies approved to do so, to be affiliated to and participate in the system designed for securing the payment of the damages to the insureds and the injured third parties. That system being the Fund for Industrial Accidents in its capacity as Guarantee Fund.

Just like the legislation on the insurance contract the European directives managed to conciliate the safeguard of the social rights for the workers with the specificities of a responsible private management subjected to the laws of the market and enjoying the advantages of a free competition.

\section{Comparison table of the social risks}

\subsection{Social risks integrated in the Social Security}

\subsubsection{Pyramid-like organisation structure}

- The management is entrusted either to semi-public institutions alone or to mutual-type "insurance bodies" which are strictly bodies receiving benefits and paying for them but are not in charge of the management.

- At the head: the ONSS (National Office of Social Security), the national body which collects and distributes the financial means collected by the different branches of the Social Security.

\subsubsection{Financial liability}

- The State is liable for the financial balance of the whole system (but the insurance bodies receiving benefits are not).

- To guarantee the financial balance: global perception of the financing allowing transfers between the Social Security branches.

- Setting-up of a Fund for the financial balance of the social security.

- National solidarity of distributive justice nature.

\subsubsection{Distribution system}

The incomings collected during a given year are directly used to pay all the expenses borne by the system during that same year (solidarity between the generations).

That financial system does not integrate nor guarantee the long-term aspect of the benefit. 


\subsubsection{Mode of affiliation}

Compulsory and not negotiated affiliation to a global system.

\subsubsection{Financing}

It is centralized and goes along the ONSS.

- It is made of: unvarying contributions independent of the risk to cover but depending on the contributor's income, and state subsidies.

- It is supported by the workers and the employers.

- Costs: the mutual benefit insurance companies are granted an exemption in matter of previous deduction.

\subsubsection{Compensation}

- For the incapacities of more than $66 \%$ (T.I. or P.I.) compensation of $60 \%$ of a maximum salary (with minima) during the first year, remained at that level for the insureds with dependent family members and reduced to $40 \%$ for the others.

- Medical costs: reimbursement on the basis of the INAMI barema but patient's contribution payable by the victim.

- No reimbursement of the travelling expenses.

\subsection{Social risk not integrated in the Social Security: Industrial Accidents}

\subsubsection{Competitive-type organisation structure}

The management is entrusted to private insurers, administrators of the risk they cover in a freely negotiated way.

\subsubsection{Financial liability}

- Each insurance company is liable for the financial balance of the branch Industrial Accidents.

- Each insurance branch must be financially self-sufficient profitability logic per product, any compensation policy prohibited.

- Compulsory investments under the control of a public body.

- Principle of risk mutuality within one same branch.

\subsubsection{Capitalization system}

Immediate building up of reserves that secure that the insurer honours his life promises of indemnification. The victims have a preferential right over established capital.

\subsubsection{Mode of affiliation}

Compulsory insurance but freely negotiated convention.

\subsubsection{Financing}

- No centralized collection but control by the Ministry of Economic Affairs. 
- It is exclusively made of premiums individualized per insured company according to the loss ratio and to the activity sector (NACE code).

- It is supported by the employers only.

- Costs: insurers are compelled to carry out tax and social deductions.

\subsubsection{Compensation}

- Compensation for T.I. of $90 \%$ of the basic remuneration.

- Compensation for P.I. of $100 \%$ (+ assistance to a third party) if the incapacity rate is higher than or equal to $10 \%$. For the P.I. lower than $10 \%$ : reduction in the benefits.

- Medical costs: reimbursement on the basis of the INAMI barema, including the patient's contribution.

- Reimbursement of the prostheses (+ maintenance, + renewal) and of the travelling expenses.

\section{Advantages of a private management}

It's difficult to take into account the advantages which the employers and the workers take in a private management. In fact, it is of the utmost relevance that the system works at best and at the lowest price and that it is built on reliable financial bases.

\subsection{For the firm}

\subsubsection{In the relationship with the insurer}

The relationship of the firm as policyholder with the insurer is facilitated and improved by the fact that the insurer already has a privileged relationship with the firm as insurer of the other enterprise insurances (Business Civil Liability - C.L. after delivery - Fire insurances).

The partnership is underlined by a common fight for a better prevention of the industrial accidents and an alleviation of their consequences. It's in the interest of the workers as well as of the firms to improve their statistics that the number and seriousness of the accidents decreases.

To reach that objective and for profitability the insurer works out technical statistics per contract (number, kind of accidents, injuries), financial statistics per contract (cost of the indemnities, expenses, ...) organizes safety training actions, with the agreement of the policyholder, trains and calls on teams of specialized engineers. Insurers freely devote 1 to $2 \%$ of their premium collection to the prevention.

Since 1951 all insurers, who are aware of the importance of prevention have created the National Association for the Industrial Accident Prevention (ANPAT) to which they alone grant funds.

\subsubsection{In the relationship with the workers}

There is no doubt that it is in the interest of the employers who finance the system that this one works well and that social peace prevails in the firm.

By fully taking care of the loss management within the context of a public law according to which the indemnification is carried out on an inclusive basis and under strong state control, the insurers prevent the firms from being in dispute with their staff or with their trade union officials. 
Moreover, within the scope of the privileged relationship with his insurer the employer has the possibility to take out complementary insurance for his staff at more attractive tariff rates which is an indisputable advantage, not only financially, but also for the staff.

\subsubsection{A better cost control}

The free competition between thirty private insurers not only invigorates the Belgian economy but also improves the competitiveness of the insured enterprises since they can ensure themselves at the best price.

The premium rate is all the more competitive since it is personalized per employer according to the safety degree reached in the firm in question.

A particularly severe policy in matters of medical control and encouragement to work resumption also leads to a better cost control.

\subsection{For the victims}

4.2.1 The effort in the matter of industrial accident prevention obviously aims at the first objective which is social protection. Prevention also means reducing the consequences of an accident, making sure that the victims are given the best health care as possible and assuring a minimum of physical and mental after-effects from their injuries. The insurers support the implementation of up-to-date and high-performance medical technology.

Moreover, the Belgian system is particularly generous concerning the indemnification level.

4.2.2. The financial reliability of the insurance companies, the severe policy in the building up of reserves for the losses under the strong control of the Fund for Industrial Accidents and of the Ministry of National Insurance, guarantee the victims the payment of their annuities even in the long term.

The capitalization system avoids carrying forward the expenses to the next years and above all guarantees the victims the payment of their indemnities and guarantees the future generations the non-debt.

Contrary to a simple bookkeeping management of a "cash flow", that dynamic approach of the costs ensures the financial reliability of the system in the long term.

\subsection{For the state}

Since the management of that system was entrusted to private insurers they have managed not only to maintain the balance between the premiums and expenses but also to reduce the cost of the insurance for the employers as the time goes by. Today the system is financially reliable but undergoes heavy levies and other forced loans on the reserves built up in industrial accidents to provide for the growing financial needs of the social security; these considerable financial transfers (about 9 billion francs since 22.12.1989) affect the financial balance and the principle of system's final responsibility. It is not normal for the management profits of an insurance and even less normal for the capital built up in favour of the victims to be allocated for objectives which have nothing to do with the insurance, instead of being profitable to the insured enterprises and to the industrial accident victims.

These transfers are systematically denounced even by the Fund for Industrial Accidents because they are nasty; they increase the expenses of the private insurance system for risks that the system does not cover. 


\section{Conclusion}

The industrial accident system owes its success without any doubt to its ability of making all those involved aware of their responsibilities:

- the insurers exercise their activity within the scope of the free competition and of a state control;

- the victim is encouraged to resume his/her duties;

- the State keeps a direct and indirect substitute role which is essential to the balance of the system;

- finally, the employers remain the real liable persons and are directly motivated to improve all preventive measures within their enterprise.

Through the prevention policy and the integration of the technological innovations private management is bearing social and economic progress, allowing us to ensure the durability of the system. 